\title{
Role of Socially-Equitable Economic Development in Creating Resilient and Sustainable Systems: COVID-19-Related Reflections
}

\author{
Adjo Amekudzi-Kennedy, Ph.D. ${ }^{1}$ | Samuel Labi, Ph.D. ${ }^{2}$ | Brian Woodall, Ph.D. ${ }^{3}$ \\ | Greg Marsden, Ph.D. ${ }^{4}$ | Emily Grubert, Ph.D. ${ }^{5}$
}

April 16, 2020

\begin{abstract}
This paper aims to provoke fundamental thinking and action around the value and importance of socially-equitable development to the economic advancement, resilience, and prosperity of communities, as we contend with the $21^{\text {st }}$ Century grand challenge of the changing climate and disasters. As local communities and the global community have experienced an increased frequency, intensity and duration of natural and man-made disasters over the past several decades, opportunities have also grown to identify and reap the benefits of socially-equitable economic development. Reflecting on the COVID-19 pandemic, we discuss the critical importance of socially-equitable economic development to the resilience and sustainability of communities and the infrastructure that supports them. To this end, we: (1) examine what constitutes socially-equitable economic development at different spatial scales of community; (2) explore whether socially-equitable development can occur at different scales of community; (3) explicate the importance of formally considering the inputs, processes, outputs and outcomes for socially-equitable development; (4) explain why the pursuit of equal distribution of the benefits and burdens of development is a necessary but not sufficient endeavor for socially-equitable economic development; (5) analyze the relationships between socially-equitable development, and resilient and sustainable infrastructure and communities; (6) explain why sociallyequitable development should be a key component of infrastructure and community resilience strategies in the $21^{\text {st }}$ Century; and, (7) explain why socially-equitable development can ultimately be viewed as a long-term strategy for prosperity.
\end{abstract}

\section{Keywords}

COVID-19, pandemic, economic development, equity, socially-equitable development, resilient and sustainable infrastructure, resilient and sustainable communities, disaster management

\section{Overview}

This paper addresses the following questions: Does equitable distribution (temporal and spatial) of economic development opportunities promote system resilience? Are relatively affluent communities generally more resilient? From a community development perspective, is economic development more efficient in outcomes in areas where such development is socially-equitable compared to areas where it is not? Does the non-discriminatory nature of pandemics elevate the importance socially-equitable development as a resilience strategy? What are the consequences of not considering equity formally in infrastructure development and services provision? In this paper, we aim to shed some light on these

\footnotetext{
${ }^{1}$ Professor, School of Civil \& Environmental Engineering, Georgia Institute of Technology, Atlanta, GA, USA

2 Professor, Lyle School of Engineering, Purdue University, Lafayette, IN, USA

${ }^{3}$ Professor, Sam Nunn School of International Affairs, Georgia Institute of Technology, Atlanta, GA, USA

${ }^{4}$ Professor, Institute of Transportation Studies, University of Leeds, UK

${ }^{5}$ Assistant Professor, School of Civil \& Environmental Engineering, Georgia Institute of Technology, Atlanta, GA, USA
} 
questions, amidst the learning opportunities that the COVID-19 pandemic offers and in the hopes that these lessons will lead to building more resilient and prosperous communities.

\section{Socially-Equitable Economic Development at the Smallest Spatial Unit of Community: The Family}

Where and when there is progress, many would probably agree that social equity is a good thing, fundamentally. For hardly does anyone raising a family send only some of their children to school with the expectation that this decision will yield the best outcome for their entire family in the long term. The natural decision is to educate all one's children, so long as one has the means to do so. Similarly, when faced with income constraints, a family will likely send all four children to medium-quality affordable schools than send only one child to a high quality and expensive school. At the family level therefore, it appears many people understand fundamentally that progress for all is better than progress for some, and that progress for all elevates the entire family, and makes the family more resilient - financially, economically and in other respects. What happens when we scale up to towns, cities, regions, and countries? Does the same thinking prevail? This common understanding at the family level does not appear to scale up all the time. And the reasons are, perhaps, not so straightforward.

There is one school of thought that the apparent dissociation of social equity from economic development, where and when this is done in oral and written discourses, does more harm than good to the advancement of socially-equitable economic development. This is because, from a holistic viewpoint, socially-equitable development is not only about redistributing pre-existing wealth or value (i.e., outcomes) - although redistribution is necessary where there is a history of disproportionate distribution of development benefits or burdens. It is also about having equitable opportunities (i.e., inputs and processes) to drive progress (i.e., outputs and outcomes). Redistributing outcomes without offering equitable inputs and processes to enable development of a different distribution of outcomes in the future, will, in the long run, lead to reversion to the prior outcomes. Thus, social equity is also as much about having the opportunity to contribute significantly to a community's existing wealth or value, and that can only happen when all have the capabilities and opportunities to make such contributions. Traditionally, efforts to promote social equity have sought: "a fair share of the proverbial pie" for everyone. How about giving comparable emphasis to making the proverbial pie larger? This can happen when those, who have hitherto had limited or no opportunities to enter the kitchen and contribute to baking that proverbial pie, are also given opportunities to develop catering skills and enter the kitchen, where they can contribute to baking a larger, and possibly increasingly delicious, pie.

Concepts of social equity and justice are varied and sundry, and perceptions of fairness and justice vary (e.g., see Khisty 1996; Brodie \& Amekudzi 2017, Martens 2017, pp. 1-34). It appears however that many can generally agree more quickly on what is inequitable, unfair or unjust than on what is equitable, fair or just. This assertion is likely to be truer in communities at smaller scales (e.g., family) than in those at larger scales (e.g., global community), and also in communities that are more homogeneous in terms of age, race and other demographic and socio-economic attributes, compared with those that are less homogeneous. In this discussion, we consider equity in economic development as comparable access to the means (i.e., the inputs and processes) of development in the long term, which may or may not result in equal outputs or outcomes in the short-term, but is expected to create equitable outcomes in the long term. The outcomes here refer to comparable access to and enjoyment of the outputs and outcomes of development. So long as there are equitable inputs and processes, there can be reasonable expectation 
of equitable outputs and outcomes, although this is not always assured. For this reason, various communities, in the past, have applied interventions periodically to ensure a more equitable distribution of development outputs and outcomes.

\section{Socially-Equitable Economic Development - Statics and Dynamics; Risks and Opportunities}

Despite long-held notions on social equity, one school of thought holds the position that social equity is not always desirable or an end in itself. In regions where poverty is predominant, the last thing most people want is static social equity, i.e., an equitable distribution of poverty. In such cases, there is a strong appetite for progress away from the status quo - and equity appears to be not so important. In fact, many would really rather not have social equity in such conditions. This seems to indicate that social equity must be qualified, and economic development cannot be taken for granted. Sociallyequitable inertia is generally undesirable. When we begin to be more explicit about the object of social equity, we change ongoing discourses about social equity in ways that are positive for the advancement of socially-equitable development in communities. For then, it will hopefully become more evident that equipping and enabling individuals and populations, in a socially-equitable manner, also contributes effectively to augmenting the economy and social quality of life (QOL), thus creating better social and economic conditions for more, or for all. This is more than a redistribution of pre-existing wealth or value, although redistribution may be necessary in some cases.

Far from being only or largely about outputs and outcomes, socially-equitable economic development is also about inputs, and processes - perhaps even more so, because inputs and processes control outputs and outcomes (even though outputs and outcomes also, in turn, affect inputs and processes). Based on observations at the scale of the family, socially-equitable economic inputs and processes, such as educating all one's children, generally result in elevated and equitable economic and social QOL outputs and outcomes for individual family members, as well as augmented overall economic and social QOL conditions (i.e., outputs and outcomes) for the entire family. Thus, at a small spatial scale of community, at least, it is clear that socially-equitable development tends to be favored over sociallyinequitable development due to the opportunities afforded by the former and the risks associated with the latter. Considering these risks and opportunities more closely, we may also realize that they are two sides of the same coin of economic development. In other words, economic development may be equitable presenting opportunities to the full range of the populations within a community, or it may be inequitable presenting systemic risks with associated vulnerabilities to various segments of the populations within a community. Upon further reflection, we may also realize that there are both static and dynamic elements associated with social equity, both of which must be formally addressed in considerations of socially-equitable development. The more dynamic elements have more to do with the inputs and processes of development, while the more static elements have more to do with the outputs and outcomes of development - although all of these elements are closely interrelated. Therefore, a comprehensive treatment of socially-equitable development must not only explicitly address economic development, it must also formally incorporate both its static and dynamic elements.

\section{Disaster and Economic Resilience; Resilient and Sustainable Infrastructure and Communities}

Resilience, the ability to prepare and plan for, absorb, recover from, or more successfully adapt to adverse events (NRC 2012), has become increasingly important over recent decades with the rise in natural and man-made disasters, worldwide, and their negative impacts widely felt in personal, built, cyber, social, economic and environmental conditions in several communities. Disasters can be and 
typically are extremely costly: in fatalities, loss of livelihoods, real property, public infrastructure, mental health, and a plethora of other personal and community assets. They can also costly in the recovery and adaptation efforts that follow, but can even be more costly when much needed adaptation does not ensue - leaving communities, their infrastructure and other critical assets vulnerable to future hazards.

The Insurance Information Institute reports that overall losses from world-wide natural catastrophes in 2019 totaled $\$ 150$ billion and 9,000 deaths. The National Oceanic and Atmospheric Administration (NOAA) reports that, since 1980, the U.S. has sustained over 250 weather and climate disasters where overall damages/costs reached or exceeded 1 billion (including CPI adjustment to 2019), with total costs exceeding $\$ 1.75$ trillion. While these are very large numbers, the death toll is however nowhere near the over 119,000 deaths over a few months reported on April 14, 2020 for the fast-moving Coronavirus pandemic (NY Times). Whichever way we look at these numbers, it is clear that both catastrophic and slow-moving disasters can be very costly. Further, disasters generally - be they slow or fast moving - are apparently no respecter of persons. They can occur anywhere and at any time and impact anyone. However, the outcomes can be very different based on different vulnerabilities, as we discuss below. Resistance, rapid recovery and adaptation can strengthen resilience against future threats, and these depend on several factors including a community's economic strength, social cohesion, institutional agility, and multifunctional infrastructure (Croope and McNeil 2011; Amoaning-Yankson \& AmekudziKennedy 2017).

The importance of a community's economic strength and its implications for socially-equitable economic development can be observed on America's mass transit crisis induced by the coronavirus pandemic. In the U.S., news reports of the impact of COVID-19 on mass transit systems (e.g., Goldbaum 2020; Taylor 2020) reveal the importance of economic wealth for resilient and sustainable infrastructure and communities. Mass transit is the lifeblood of many big cities and metro areas. It moves millions of people every day, supporting economic development, improving the social QOL, and helping to preserve metropolitan air quality. Large-scale public transit systems in several metropolitan areas including New York, San Francisco, Washington DC and Philadelphia, which constitute critical assets to the nation's sustainable development, are struggling under the weight of the coronavirus pandemic. Revenues are plummeting as commuters nationwide are instructed to stay home to prevent the spread of the virus (McFarland 2020). In spite of the demonstrated short-term vulnerability of these transit systems to the pandemic, there is no doubt that they will remain critically important to the nation, in the long term.

There is general agreement that an economic bailout is necessary to keep the nation's transit system from becoming a COVID-19 casualty. The president of the American Public Transportation Association (APTA), Paul Skoutelas, discussed the colossal impact of the global pandemic on the nation's mass transit systems, as APTA called on Congress to provide $\$ 16$ billion in emergency funds to transit agencies to help them address the crisis from the coronavirus (McFarland 2020). The Chicago Sun Times Editorial Board notes that the country has nearly 1,000 transit systems - all struggling with steep COVID-19 related declines in ridership and revenue, along with increased maintenance and disinfection costs (CST Ed. Board 2020). The historic $\$ 2$ trillion coronavirus relief bailout passed by the U.S. Congress and signed into law in March 2020 (Zeballos-Roig 2020) will address the nation's transit system resilience and sustainability threats, at least for some appreciable but finite period of time. Clearly, such infusions of economic capital to facilitate resistance and recovery in the face of existential and other threats highlight not only the importance of economic resilience to sustainable infrastructure and development, but also reveal the nexus between economic resilience, resilient and sustainable infrastructure, and, 
sustainable development (Amekudzi et al. 2020). Social equity, without economic resilience, may not be so effective in facilitating short-term resilience of the nation's mass transit system. Thus, the nation's mass transit experiences with COVID-19 reflect that we cannot take economic resilience for granted. We must build economic resilience doggedly, systematically and assuredly, particularly in the context of the $21^{\text {st }}$ Century grand challenge of climate change and disasters.

At the same time, inequitable economic development and economies could also introduce notable inefficiencies with respect to community development and perpetrate inequalities in interventions for short-term resilience. For example, in the U.K., just 1\% of English residents are responsible for nearly a fifth of all flights abroad. Further, the $10 \%$ most frequent flyers in England took more than half of all international flights in 2018. At the same time, $48 \%$ of the population did not take a single flight abroad in the last year (Kommenda 2019). Any infusions of funds to bailout the airline industry would as a result be inequitable. Thus, crises shine a light and raise questions about what is provided, what is necessary and who should benefit from government support. In the U.K. and several other places, the reality on the ground is that maintaining public transport services is essential for the lower paid nurses, cleaners, grocery distributors and trash collectors to get to work. This is what is keeping society functioning. However, the voices of these workers in arguing for the distribution of tax revenues to support their services may not be heard loudly. Without explicit attention to addressing social equity at times of system stress there are strong risks that the same biases which infuse inequity into these systems in the first place will be continued, or exacerbated.

Socially-equitable economic development occurring at different temporal scales (i.e., over years, decades, centuries and millennia) and at different spatial scales (i.e., at the family, municipality, regional, national and global levels) infuses higher levels of resilience into communities and systems against various hazards in the short and long term.

\section{Environmental, Social and Economic Justice in the U.S.}

"The government built highways that carried white families to new suburban neighborhoods where minorities often were not allowed to live; it provided mortgage loans that minorities were not allowed to obtain; and even after explicit discrimination was declared illegal, single-family zoning laws continued to exclude low-income families, particularly minorities." (NY Times Ed. 2020).

The history of institutionalized discrimination, reflected in systemic and disproportionate distribution of the benefits and burdens of development (i.e., economic, environmental and social) in the U.S. (see, for example, Bullard and Johnson 1997), has led to a body of laws, policies and regulations in an attempt to correct persisting and persistent inequities. Today, more than 50 years after the Civil Rights Act of 1964, the COVID-19 pandemic is reminding us that these disproportionate benefits and burdens of development still persist. "In Michigan where the pandemic hit early and hard, African Americans make up just $14 \%$ of the state's population, but $40 \%$ of the dead." (NY Times Ed. 2020). The data tell similar stories elsewhere. "Seventy percent of coronavirus deaths in Milwaukee have been African Americans, even though African Americans are less than a third or the county's population. Similarly, in Chicago, African Americans are 30 percent of the population, but 69 percent of the coronavirus deaths; and in Louisiana, African Americans are 32 percent of the population but 70 percent of coronavirus deaths." (Haslett 2020). COVID-19 is illuminating pre-existing disparities in the country, and the vulnerabilities that come with them. "Black people are more likely than other Americans to have underlying health issues like diabetes, heart disease and lung disease. Blacks also are statistically more likely to live in 
poverty, with less access to health insurance." "Underlying health issues and limited access to treatment also partly explain why so many coronavirus victims are black." (Blake 2020). And, a lot of these underlying health issues are themselves due to systemic and racialized environmental injustice (Hornyak 2020; Owens et al. 2008).

While Environmental Justice (EJ) predates the 1980s, EJ became a national issue in the early 80 s when a North Carolina community protest led to a federal investigation on the location of toxic waste landfalls in the South U.S. The resulting study by the U.S. Government Accountability Office revealed that a disproportionately high number of such facilities were sited in low-income and minority neighborhoods throughout the region (Owens et al. 2008). The1994 EJ Executive Order (12898) of the Clinton Administration effectively brought together Title VI of the Civil Rights Act of 1964, which focuses on nondiscrimination, and the National Environmental Policy Act (NEPA) of 1970 which focuses on protecting the natural environment. These two pieces of legislation establish the basis and authority for the concept of EJ. EJ requires all federally funded agencies to identify and address disproportionately high and adverse human health and environmental effects of their programs, policies and activities on minority and low-income populations. Subsequently, federal agencies issued regulations addressing EJ.

The United States Environmental Protection Agency (USEPA) defines environmental justice as the fair treatment and meaningful involvement of all people regardless of race, color, national origin or income with respect to the development, implementation, and enforcement of environmental laws, regulations and policies (USEPA 1998). The Federal Highway Administration and the Federal Transit Administration identify three fundamental principles of EJ related to burdens, process, and benefits: (1) To avoid, minimize or mitigate disproportionately high and adverse human health and environmental effects, including social and economic effects, on minority populations and low-income populations; (2) To ensure the full and fair participation of all potentially affected communities in the transportation decision-making process; and, (3) To prevent the denial of, reduction in, or significant delay in the receipt of benefits by minority and low-income populations (FHWA 2010). In the field of transportation, ongoing EJ implementation is supported by efforts to increase the involvement of historically marginalized populations in the transportation planning and decision-making process, and, the development and application of supporting tools (see for example, Amekudzi et al., 2010, Labi 2014, pp. 929-973, and Sinha and Labi 2007, pp. 427-447), notwithstanding methodological challenges (see for example, Amekudzi \& Dixon 2001, Amekudzi et al. 2010, Brodie \& Amekudzi-Kennedy 2017).

While EJ regulations and practice constitute a tremendous effort to address the cumulative disproportionate distribution of the benefits and burdens of development, practically, these efforts can address the outputs and outcomes without sufficiently attending to the inputs and processes of development. Hence, these efforts may be necessary but not sufficient to create socially-equitable economic development. The EJ process, intended to redistribute benefits and burdens, if it does not also redistribute the means (i.e., inputs and processes) for creating those benefits and burdens will also do the following: (1) It will continue to require redistribution in order to approach or achieve equitable outcomes; (2) It will not necessarily lead to socially-equitable development always (i.e., the inputs and processes of development); at best it may lead to socially-equitable outcomes of development (with the need for continual redistribution of outputs and outcomes to maintain equity); and, (3) It may leave several communities operating below their full capacities or potential with respect to making the best use of their talents, strengths and other assets and resources to contribute substantively in the overall development process and achieve the highest levels of prosperity. Further, relying on continual 
redistribution processes also relies on the assumption that those in power are interested in and capable of ensuring equity of development outcomes, which has not always been true in practice.

When one considers the family, EJ would be analogous to educating one of two children in a family to the university level and the other child only to the elementary school level, and then attempting to redress the long-term disproportion by leaving in a will equal amounts of wealth to both children. Needless to say, one child would most likely be far ahead of the other - in earning power, tax contributions to support community development, the ability to provide for and support other family members and thus enhance the broader family's economic and social resilience; the ability to afford health insurance, and several other "benefits and burdens" at the scale of the family. Surely, a bigger piece of pie, solely for the eating, does not nearly nor fully compensate for one's inability to enter into the kitchen and contribute to baking the pie. In the kitchen, one may decide to bake new pies, more pies, bigger pies, increasingly delicious pies ... the possibilities are endless. And for a family, the more competent people there are in the kitchen, the more pies (or the larger the pie) they can make for the benefit everyone.

\section{Socially-Equitable Economic Development - Possibilities and Performance Indicators}

A review of time trends of the Gini coefficient of inequality and per capita gross domestic product (GDP) can shed some light on the extent to which a community's economic development has been socially equitable. In general terms, the Gini coefficient is a measure of income inequality, ranging from zero to one, with values closer to one indicating greater inequality. The GDP is the value of all the goods and services that an entity (typically a country) produces in a given timeframe (typically a year). While these are not complete indicators for tracking sustainable development (i.e., we must also understand how development is affecting the natural environment), they can be used together to gain insights into the extent to which the wealth that being created by a community is being distributed across the population over time. In other words, these two measures, viewed over time, shed light on the spatial and temporal distribution of economic wealth for communities at various scales - countries, regions, cities, and others. A recent study on institutions, infrastructure and the socio-economy (Amekudzi et al. In Review) reveals that, with the exception of very few countries, most countries that have grown their economic wealth in the 50 years between 1960 and 2010 have also seen this wealth become more concentrated in the hands of fewer people. Japan and Denmark are two examples of the few countries where increased per capita GDP has been accompanied by wealth distribution across the entire population over this period. In other words, there has been a per capita increase in GDP with a simultaneous decrease in the Gini Coefficient.

The figure below (Figure 1) shows the Gini and GDP trajectories for the U.S., Japan and Denmark in this 50 -year period. In all three cases, normalized growth in GDP per capita has been robust, with decreasingly equitable outcomes in the U.S. and increasingly equitable outcomes in Japan and Denmark. The story these data tell is that it is possible to achieve robust growth in the economy while still achieving robust growth in social equity. These data demonstrate that the two sides of the coin of economic development, that is, socially-equitable economic development and socially-inequitable economic development, can and do scale up after all. Both types of economic development are possible; the latter more common, the former increasingly necessary for system resilience and, thus, prosperity in the long term - particularly in the context of climate change and the increasing frequency, intensity and duration of disasters. 


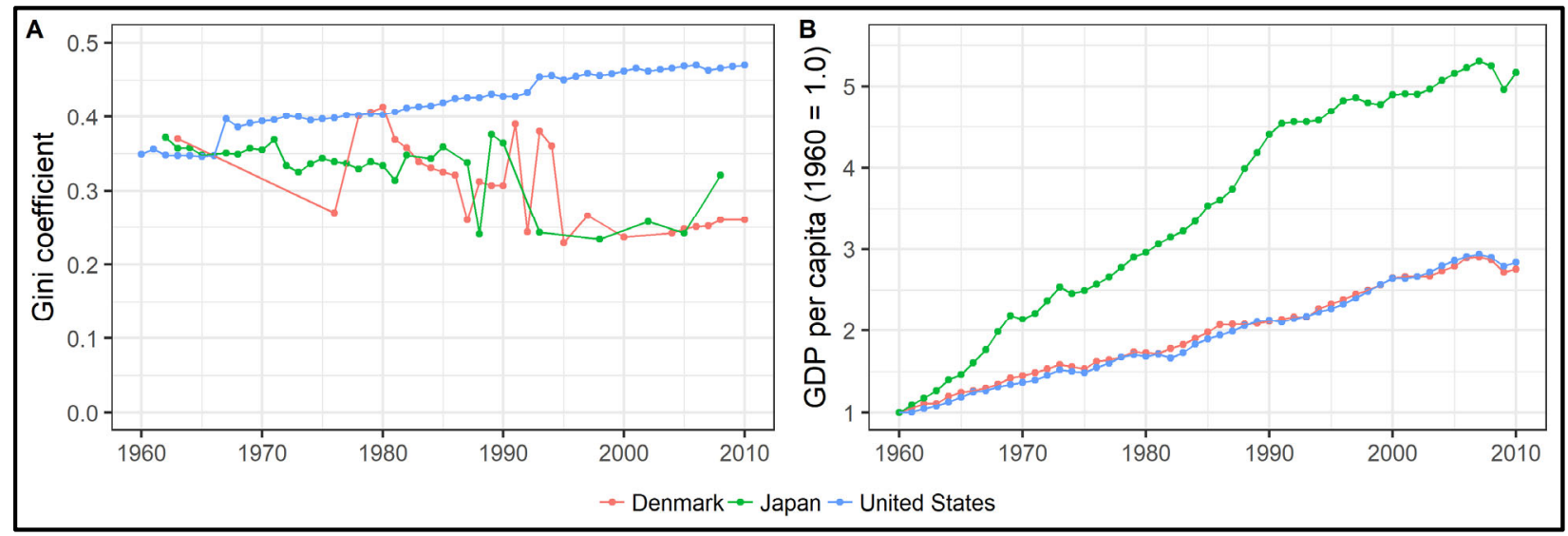

Figure 1: Time trends in the Gini coefficient of inequality (A) and normalized GDP per capita measured in 2010 US dollars (B) [Sources: Gini coefficients from Milanovic (2014) and GDP from World Bank (2017). (Source: Amekudzi-Kennedy et al. In Review)

According to Quinn and Kumar (2014), historical accounts of influenza pandemics and contemporary reports on infectious diseases clearly demonstrate that poverty, inequality, and social determinants of health create conditions for the transmission of infectious diseases, and existing health disparities or inequalities can further contribute to unequal burdens of morbidity and mortality. They argue that international partners, from WHO to individual countries, must grapple with the social determinants of health and existing health inequalities and extend their vision to include these factors so that disease that may start among socially disadvantaged subpopulations does not go unnoticed and spread across borders. While these arguments are made to address the challenges posed by inequalities to global health security, similar arguments may be made with respect to national health security and municipal health security in counties and cities with persistent or persisting inequalities and vulnerabilities to disease stemming from systemic disparities in access to healthcare and other goods and services.

Farmer (1996) observes that inequalities have powerfully sculpted not only the distribution of infectious diseases, but also the course of disease in those affected. O'Sullivan \& Bourgoin (2014) conducted a literature review that indicates that in the context of pandemic, there is a social gradient of risk, based on social vulnerabilities that are likely to lead to increased exposure to the contagion, risk of basic human needs not being met, insufficient support, or inadequate treatment. They organize this literature review according to several of the risk categories within the Social Determinants of Health (SDH) Framework outlined by Mikkonen and Raphael (2010), based on WHO's work on SDH: (1) Income and Income Distribution; (2) Social and Physical Environment; (3) Education and Literacy; (4) Employment and Working Conditions; (5) Early Life Income and Child Development; (6) Ethnicity, Culture and Language; (7) Age and Disability; (8) Gender; and (9) Access to Health Services. Per WHO's SDH framework, the primary factors that shape health of people all over the world are not medical treatments or lifestyle choices but rather the living conditions they experience. According to WHO, the SDH are the conditions in which people are born, grow, work, live, and age, and the wider set of forces and systems shaping the conditions of daily life. These forces and systems include economic policies and systems, development agendas, social norms, social policies and political systems (WHO). Future studies investigating the relationship between socially-equitable development and a wide range of system 
resilience measures, and applying emerging evidence in planning and decision making can add value in the development of more resilient communities and supporting infrastructure and services.

\section{Climate Hazards - No Respecter of Persons; Vulnerability Reduction Leads to Increased Resilience}

Current and past disasters have shown that the most vulnerable individuals and groups in communities determine the lower limits of system resilience for the whole community - to various threats and hazards. These vulnerabilities come in many forms: climate hazards, pandemics, lack of economic resilience, systemic vulnerabilities from systemic socially-inequitable development, lack of social cohesion, lack of institutional agility, lack of multifunctional infrastructure and other factors. Reducing these vulnerabilities strengthens system resilience. Commenting on the impacts of the pandemic on the country's most vulnerable, a NY Times editorial notes: "The magnitude of the crisis is determined not just by the impact of the precipitating events but also by the fragility of the system it attacks. Our society was especially vulnerable to this pandemic because so many Americans lack the essential liberty to protect their own lives and the lives of their families. The nation was ailing long before the coronavirus reached its shores." (NYT 2020). Reducing the vulnerabilities of the most vulnerable members in a community goes a long way in strengthening the resilience of the whole community. Likewise, reducing the vulnerabilities of the most vulnerable components of a community's infrastructure system also goes a long way in strengthening the resilience of the entire infrastructure system, and the communities it serves. Therefore, the maxim: a chain is as strong as its weakest link clearly applies, in many cases, to community and infrastructure resilience - at various spatial scales (i.e., family, town, city, megacity, state, region, megaregion and, global community), and, temporal scales (i.e., years, decades, centuries, millennia).

\section{Relationship between Socially-Equitable Development and Sustainable Development}

Arguably the most cited definition of sustainable development, the United Nation's definition recognizes intergenerational and intra-generational equity as fundamental components of development that is sustainable (UNEP 1987): development that meets the needs of the present without compromising the ability of future generations to meet their own needs. The American Society of Civil Engineers' (ASCE) Code of Ethics calls out equity as a fundamental canon, requiring that engineers shall treat all persons fairly and encourage equitable participation for all. All over the world, several international agencies, nations, cities, engineering professional societies and other authoritative bodies have adopted social equity as a policy priority for sustainable development (see, for example, World Bank 2003, UK Engineering Council 2009, and, Labi 2014, pp. 944-945). There is growing acknowledgment that social equity is intimately intertwined with economic advancement. Indeed, when approached through inputs, processes, and, outputs and outcomes, socially-equitable economic development can foster socially-equitable advancement that creates better conditions for all, and, support the development of system resilience - economic, social and infrastructure - in the long term. Thus, in this $21^{\text {st }}$ Century, where we are experiencing growing frequency, intensity and duration of disasters, it is really in the interest of municipalities and nations around the world to understand and apply best and effective practices for socially-equitable economic development. This is a cornerstone for resilient and sustainable communities and infrastructure.

Socially-equitable development is about continuing and equitable opportunities, that is, equitable inputs and processes that allow for the equipping and participation of entire populations in advancing the economy and enjoying its benefits. Will it result in equal outcomes in the long term? Probably not. In 
the same way, providing equitable opportunities for all one's children in a family does not necessarily lead to equality among them in their adulthood. What it does, however, is to foster equitable outcomes, assuming all goes well as expected: comparable outcomes for all of one's children and a higher level of economic resilience for one's family overall. From the standpoint of public infrastructure, the mechanisms, including "influence pathways" (Fischer 2014), through which socially-equitable development can occur include investments in infrastructure that leads to comparable system performance for all populations - spatially and temporally. And this performance must be holistic; holistic system performance is evaluated not only by outcome measures or indicators but also by input, process, and, output measures or indicators.

\section{Concluding Remarks}

The dynamics of the COVID-19 pandemic playing out in community public health, mass transit resilience and sustainability, and, economic and community resilience, highlight the critical importance of sociallyequitable economic development. In particular, the dynamics of the pandemic are highlighting the following: (1) Communities at various scales (i.e., towns, cities, nations, regions) with higher levels of economic wealth, more equitably distributed temporally and spatially, will generally tend to be more resilient to existential and other threats; (2) Where communities are comparably affluent and on an increasing trajectory of affluence, those with more equitably distributed wealth and higher floors of minimum wealth are probably more likely to be more resilient; (3) From a community development (i.e., municipal, state, regional) and public infrastructure perspectives, it appears socially-equitable economic development leads to more efficient outcomes, with respect to system resilience, than does inequitable economic development; (4) Both socially-equitable and socially-inequitable development scale up, and hence, communities can learn and implement best and effective practices for socially-equitable development as a resilience strategy for infrastructure, economic and community development at higher scales; (5) The fact that climate, pandemic and other threats are no respecter of persons elevates the importance of socially-equitable development as a resilience strategy; (6) Infrastructure policymaking, planning, design and construction, maintenance and renewal approaches, if they do not formally incorporate equity considerations, will lead to the development of less resilient infrastructure and communities in the long term, with avoidably higher opportunity costs; and, finally, (7) There is growing evidence and acknowledgement that social equity is intimately intertwined with economic advancement. Indeed when approached through formal considerations of inputs, processes, outputs and outcomes, socially-equitable economic development can foster not only socially-equitable advancement that creates better conditions for all but also support the development of system resilience - economic, social and infrastructure - in the long term. History has shown, as the NY Times Editorial Board acknowledges, that the U.S. has emerged stronger and more resilient from some of its darkest hours. Lessons from COVID-19 illuminate existing opportunities to reduce the risks of sociallyinequitable development by taking advantage of ample opportunities for socially-equitable development.

\section{Acknowledgements}

The authors wish to acknowledge and thank Dr. Jamie M. Fischer, Director of Transportation Performance \& Innovation (TPI) for the State Road \& Tollway Authority, Georgia Regional Transportation Authority, and Atlanta-region Transit Link Authority, for her comprehensive and insightful review of the manuscript. The authors remain exclusively responsible for the contents of this paper. 


\section{References}

Amekudzi, A. A., and K. K. Dixon. Development of an Environmental Justice Analysis Methodology for Georgia Department of Transportation's Multimodal Transportation Planning Tool. Proceedings of the $8^{\text {th }}$ Transportation Research Board Conference on Planning Applications, Corpus Christi, Texas, April 2001.

Amekudzi-Kennedy, A.; Labi, S.; Woodall, B.; Chester, M.; Singh, P. Reflections on Pandemics, Civil Infrastructure and Sustainable Development: Five Lessons from COVID-19 through the Lens of Transportation. Preprints 2020, 2020040047 (doi: 10.20944/preprints202004.0047.v1

Amekudzi, A., Smith, M., Brodie, S., Fischer, J., Ross, C. Impacts of Environmental Justice on Transportation: Applying the Environmental Justice Maturity Model to Benchmark Progress. Transportation Research Record, Journal of the Transportation Research Board, No. 2320, December 2012, pp. 1-9.

Amekudzi-Kennedy, A., Woodall, B., Karner, A., Akosa, A., Franklin, H., Simao, J.L., Gudmundsson, H., and J. Smith-Colin. Institutional Arrangements, Transportation System Investments, and Socio-Economic Outcomes: Affecting the Development of Shared Regional Prosperity. Journal of Urban Planning and Development, American Society of Civil Engineers. Submitted: April 2019. Under Review.

American Society of Civil Engineers. Code of Ethics. https://www.asce.org/code-of-ethics/ Accessed April 9, 2020.

Amoaning-Yankson, S., and A. Amekudzi-Kennedy. Transportation System Resilience: Opportunities to Expand from Principally Technical to Socio-Technical Approaches. Transportation Research Record. Journal of the Transportation Research Board. No. 2604, DOI: 10.3141/2604-04, 2017.

Blake, J. Black Americans are being hammered by a double pandemic. CNN. April 12, 2020.

Brodie, S., and A. Amekudzi-Kennedy. A Performance-Based Methodology for Evaluating Equity for Transportation System Users. Transportation Research Record. Journal of the Transportation Research Board. No. 2605. DOI: 10.3141/2605-08, 2017.

Bullard, R. D., and G. S. Johnson (1997) (Eds.). Just Transportation. Dismantling Race \& Class Barriers to Mobility. New Society Publishes, Gabriola Island, BC and Stony Creek, CT.

Croope, S.V., McNeil, S. Improving resilience of critical infrastructure systems postdisaster: recovery and mitigation, Transportation Research Record, Journal of the Transportation Research Board, 2234 (1), 3-13, 2011.

Editorial Board, Chicago Sun Times. Bailout might keep public transit from becoming a coronavirus casual ty, but more help will be needed soon. Chicago Sun Times. March 25, 2020. < https://chicago.suntimes.com/2020/3/25/21191564/trillionbailout-transit-money-coronavirus-stimulus-federal-government-trump-cta-rta-metra-pace $>$

Editorial Board. The America We Need. NY Times. April 9. 2019.

European Centre for Disease Prevention and Control. An agency of the European Union. COVID-19-Deaths by selected criteria. https://qap.ecdc.europa.eu/public/extensions/COVID-19/COVID-19.html. Accessed April 11, 2020.

Farmer P. Social inequalities and emerging infectious diseases. Emerging Infectious Diseases 1996; 2(4):259-269

Federal Highway Administration. Environmental Justice. www.fhwa.dot.gov.gov/ENVIRONMENT/EJ2.HTM. Accessed Sept. 30, 2010.

Fischer, J. M. Transportation Performance Management for Livability and Social Sustainability: Developing and Applying and Conceptual Framework. A Dissertation presented to the Academic Faculty by Jamie Montague Fischer, in partial fulfillment of the requirements for the degree of Doctor of Philosophy in Civil Engineering. Georgia Institute of Technology, December 2014.

Goldbaum, Christina. M.T.A. Citing Huge Drop in Riders, Seeks \$4 Billion for Virus Bailout. The New York Times. Published March 17, 2020.

Haslett, Cheyenne. CDC releases new data as debate grows over racial disparities in coronavirus deaths. abc NEWS, abcnews.go.com, April 8, 2020.

Hornyak, T. (2020), Air pollution can worsen the death rate from COVID-19, Eos, 101, https://doi.org/10.1029/2020EO142660. Published on 10 April 2020.

Insurance Information Institute. Facts + Statistics: Global Catastrophes. < https://www.iii.org/fact-statistic/facts-statisticsglobal-catastrophes>, Accessed April 4, 2020.

Khisty, J. C. Operationalizing Concepts of Equity for Public Project Investments. Transportation Research Record. No. 1559. January 1, 1996, 94-99. Transportation Research Board.

Kommenda, N. 1\% of English residents take one-fifth of overseas flights, survey shows. The Guardian, September 25, 2019. 
Labi, S. Introduction to Civil Engineering Systems - A Systems Perspective to the Development of Civil Engineering Facilities. John Wiley \& Sons, Inc., 2014.

Martens, K. Transport Justice: Designing Fair Transportation Systems, Routledge, 2017.

McFarland, M. America's public transit systems are going to need a bailout too. CNN. Business. Posted March 23. < https://www.wral.com/americas-public-transit-systems-are-going-to-need-a-bailout-too/19025731/> Accessed: April 4. 2020.

Mikkonen, J., and D. Raphael. (2010). Social Determinants of Health: The Canadian Facts. Toronto: York University School of Health Policy and Management, 2010. http://www.thecanadianfacts.org/. Accessed April 15, 2020.

Milanovic, B. Description of All the Ginis Dataset. World Bank, 2014.

National Research Council. Disaster Resilience. A National Imperative. The National Academies. The National Academies Press, 2012: Washington, D.C.

National Oceanic and Atmospheric Administration (NOAA) National Centers for Environmental Information (NCEI). U.S. BillionDollar Weather and Climate Disasters (2020). https://www.ncdc.noaa.gov/billions/, DOI: 10.25921/stkw-7w73

New York Times. Coronavirus Map: Tracking the Global Outbreak. April 10, 2020. Accessed at: https://www.nytimes.com/interactive/2020/world/coronavirus-maps.html\#map

New York Times, Editorial Board. The America We Need. Opinion. April 9, 2020. https://www.nytimes.com/2020/04/09/opinion/coronavirus-inequality-america.html

O'Sullivan T., and M. Bourgoin. Vulnerability in an influenza pandemic: Looking beyond medical risk. Public Health Agency of Canada; 2010. https://homelesshub.ca/sites/default/files/attachments/Lit\%20Review\%20\%20Vulnerability\%20in\%20Pandemic FINAL.pdf Accessed April 15, 2020.

Owens, E., Goodwin, G., Lewis, C., and J. Mallory. An Evaluation of Environmental Justice and Environmental Equity: Laws and Issues that Affect Minority and Low-Income Populations. SWUTC/08/167921-1. Southwest Region University Transportation Center, College Station, Tex., 2008.

Quinn, S. C., and S. Kumar. Health Inequalities and Infectious Diseases Epidemics: A Challenge for Global Health Security. Biosecurity and Bioterrorism: Biodefense Strategy, Practice and Science. Sep 1, 2014: 12 (5): 263-273.

Sinha, K., and S. Labi. Transportation Decision Making: Principles of Project Evaluation and Programming, 2007, John Wiley \& Sons, Inc.

Taylor, Kate. No Bus Service. Crowded Trains. Transit Systems Struggle With the Virus. The New York Times. Published March 17, 2020.

United Kingdom Engineering Council. Guidance on Sustainability, 2009.

United States Environmental Protection Agency (USEPA). Office of the Federal Activities. Final Guidance for Incorporating Environmental Justice Concerns in EPA's NEPA Compliance Analysis. April 1998.

United Nations. Report of the World Commission on the Environment and Development: Our Common Future. 1987.

World Health Organization (WHO). Social Determinants of Health. https://www.who.int/social determinants/en/ Accessed April 15, 2020.

World Bank Group (US). Population Database. https://data.worldbank.org/indicator/SP.POP.TOTL Accessed April 7, 2020.

World Bank. Social Analysis Sourcebook: Incorporating Social Dimensions into Bank-supported Projects. Social Dev. Dept., Washington, D.C., 2003.

World Bank. World Development Indicators. https://data.worldbank.org/data-catalog/world-development-indicators. Accessed Oct. 10, 2017.

Zeballos-Roig, Joseph. Trump signs corona virus economic relief bill into law, which includes checks for Americans and Business Loans. Business Insider, March 27, 2020. https://www.businessinsider.com/trump-signs-coronavirus-economic-relief-aidbill-checks-for-americans-2020-3, Accessed March 2020. 